Chapter 5

\title{
Oral Squamous Cell Carcinoma in Young Population - Risk Factors, Clinical Presentation, and Prognosis
}

\author{
Ligia Buloto Schmitd, Kellen Cristine Tjioe, \\ Agnes Assao and Denise Tostes Oliveira \\ Additional information is available at the end of the chapter \\ http://dx.doi.org/10.5772/60712
}

\section{Introduction}

The oral squamous cell carcinoma is a particular type of cancer classically described as a tobacco- and alcohol-related disease affecting mostly elderly male patients. However, epidemiologic studies have demonstrated an increasing incidence of young individuals with oral cancer. Interestingly, the clinicopathological profile, etiology, risk factors, and outcome of patients with early-onset disease seem to present several differences compared to late-onset oral carcinoma and these discrepancies are discussed below.

\section{Clinical manifestations}

Retrospective studies including elderly and young patients have shown that the incidence of squamous cell carcinoma (SCC) of the mouth in young people is low but presents an increasing tendency [1]. In fact, there is certain heterogeneity of the cutoff age employed in the studies. Most authors consider young patients as those who are under 40 or 45 years [2-6] whereas few investigations select individuals under 20 or 30 years [7-9]. The incidence of oral cancer in patients younger than 40 years of age varies between $0.4-3.6 \%$, but it can reach $6.7 \%$ in studies considering 45 years as the cutoff point [10]. Due to its rarity, most investigations deal with a small sample of patients, and conflicting results have been published regarding the epidemiological aspects of oral SCC.

The clear male predominance found in late-onset lesions is not found in the early-onset counterparts. Men are still more affected than women but only slightly more, with a F:M ratio 
varying from 1:1.2 to 1:4.9 [11, 12]. These data show an evident augmentation in the number of young women affected by oral SCC. The differences between sex distribution previously observed may be due to smoking and drinking habits, which are more socially acceptable for both genders currently [10].

The most common oral subsite for SCC in young patients is the tongue, with $39-77 \%$ of the cases $[13,14]$. A study conducted in Taiwan found a higher incidence of oral SCC in the buccal area $(53.6 \%)$ in comparison with the tongue $(42,8 \%)$, but betel chewing was common among these patients [15]. Other retrospective reports in Germany and Brazil showed a slightly higher incidence of oral SCC in the floor of the mouth, followed by the mobile tongue $[12,16]$.

The typical clinical appearance of oral SCC in young patients is an ulcer, often intermixed with white plaque and/or reddish areas. Kuriakose et al. [17] noted that lesions in young patients were predominantly invasive as compared with the exophytic lesions found in older patients $[10,17]$. On the other hand, Falaki et al. [18] reported exophytic lesion with ulcer as the most common clinical presentation in younger individuals.

Figures 1 and 2 illustrate a 35-year-old young man who presented with a white plaque intermixed with erythroplastic areas in the right border of the tongue. The duration of the lesion was of one year, and the patient reported slight pain. Moreover, the individual did neither consume tobacco nor alcohol. Incisional biopsy confirmed the diagnosis of SCC that was staged lately as T2N0M0. The patient was submitted to partial glossectomy with supraomohyoid selective neck dissection of the same side and radiotherapy. The one-year followup was uneventful.

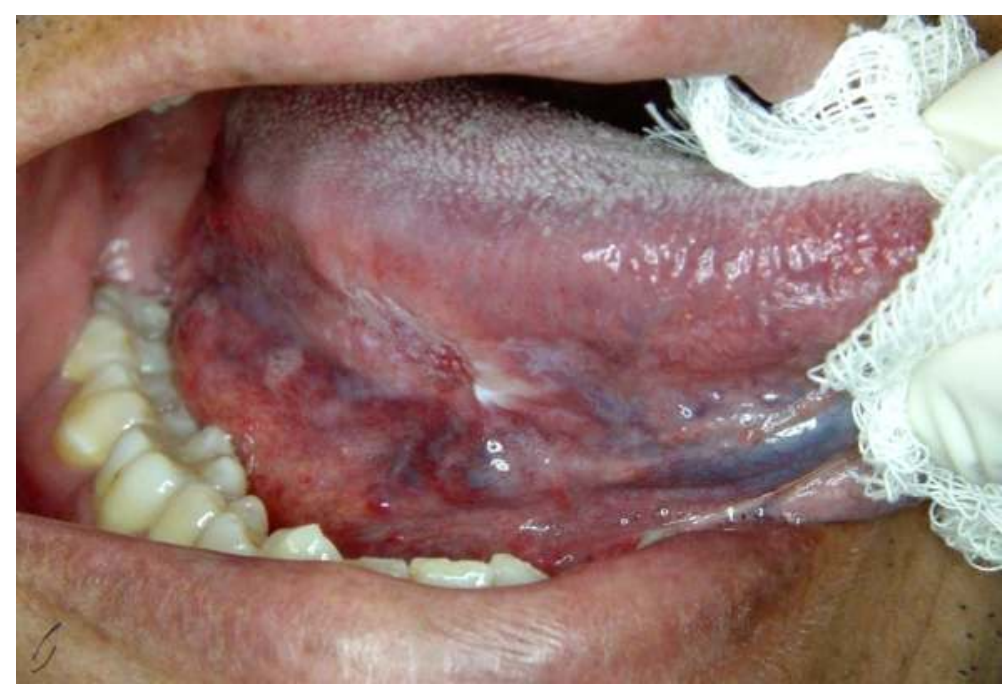

Figure 1. Clinical features of oral SCC in young patient - presence of white plaque and ulceration at the right lateral surface of the mobile tongue of a 35-year-old patient. 


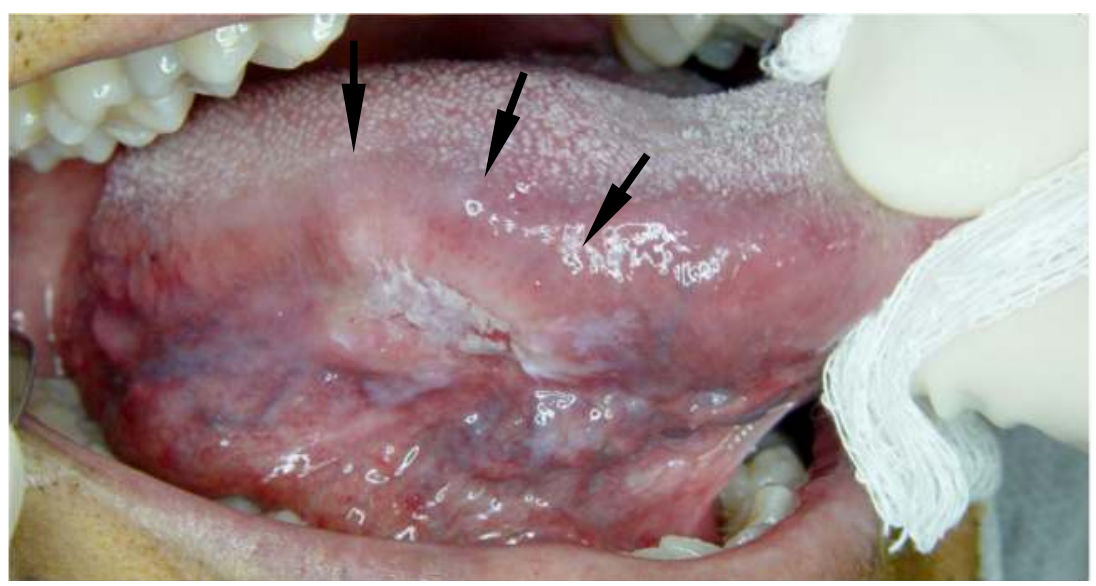

Figure 2. Arrows indicate the lesion showed in Figure 1. Elevated and indurated borders were confirmed by palpation, demonstrating the infiltrative growth of the tumor.

Regarding the symptoms, initial local pain is uncommon [19]. Other signs and symptoms can be dysphagia, weight loss and otalgia (26.5\%, $26.6 \%$ and $37.5 \%$, respectively) [20], but they seem to be related to the size and anatomic location of the tumor. The duration of the symptoms before diagnosis can vary, but reported data show that most of the patients had early stage disease at the moment of diagnosis, that is, from $52-95 \%$ of the patients presented with lesions graded as T1 or T2, usually without neck metastasis [13, 21]. Fang et al. [22] reported that $80 \%$ of patients younger than 40 years-old with oral SCC presented lesions staged as T1 or T2 and only one tumor with positive node metastasis, appearing to be weakly aggressive at diagnosis. However, the clinical result was poor, as 10 (66.7\%) patients exhibited recurrence and five (33\%) patients succumbed to the disease [22].

The delay before diagnosis is usually between few weeks and 10 months [23, 24].

\section{Microscopic findings}

The microscopic features that define an oral SCC do not differ between young and old patients. SCC is an invasive epithelial neoplasm with varying degrees of squamous differentiation. Disorganized stratified squamous epithelium forming strands and islands of bizarre epithelial cells presenting severe dysplasia infiltrating subjacent submucosa is observed. Dyskeratosis, polymorphism, hyperchromatism, atypical mitosis and loss of nucleolus-nucleus and nucleuscytoplasm ratio are also marked cellular characteristics [25], as shown in Figures 3 and 4.

The tumors are traditionally graded into well, moderately, and poorly differentiated SCC. According to the World Health Organization (WHO), well-differentiated carcinoma resembles closely normal squamous epithelium. Moderately differentiated carcinoma contains distinct nuclear pleomorphism and mitotic activity, including abnormal mitosis, and there is normally 
less keratinization. In poorly differentiated carcinoma, immature cells predominate, with numerous typical and atypical mitosis, and minimal keratinization. Most of the SCCs are moderately differentiated [25]. The studies in young population also showed a higher incidence of moderately differentiated oral tumors, ranging from $40.9 \%$ to $70 \%$ of the sample [7, 20, 26-29]. Hilly et al. [8] and Garavello et al. [27] found worse prognosis and higher indexes of moderately and poor differentiated tumors in their sample. Controversially, Hyam et al. [30] found similar prognosis associated with $67 \%$ of poorly differentiated tumors. Grading by differentiation is of limited prognostic value, as compared to the pattern of invasion [25].

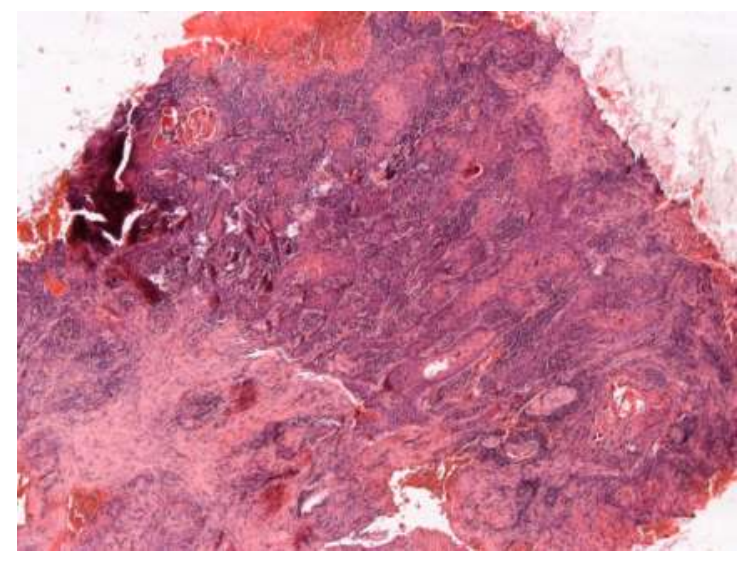

Figure 3. Neoplastic squamous epithelium infiltrating subjacent submucosa (H\&E original magnification X50).

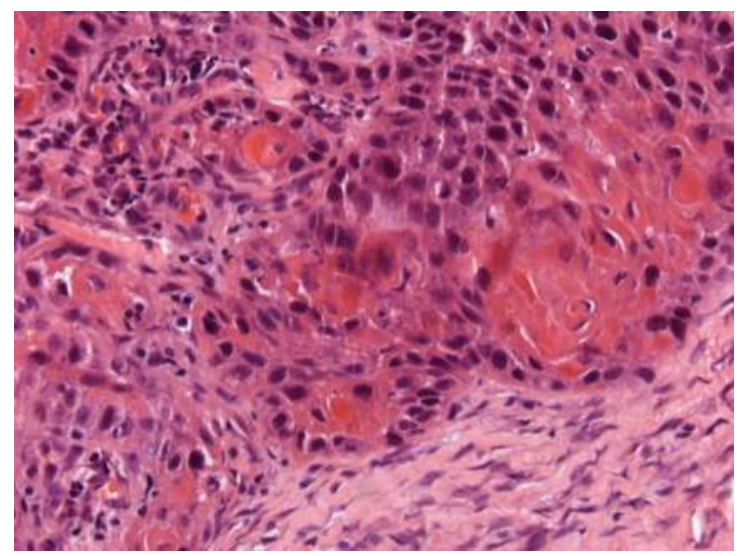

Figure 4. Detail of neoplastic epithelial cells with atypical mitotic figures, dyskeratosis, and loss of nucleolus-nucleus and nucleus-cytoplasm ratio; neoplastic cells presenting polymorphism and hyperchromatism (H\&E original magnification X400). 


\section{Etiology/risk factors}

\subsection{Tobacco and alcohol}

In recent years, an increasing number of young patients, who declare to never having smoked or consumed alcohol excessively, are diagnosed with oral SCC [17, 31]. Tobacco smoke and alcohol abuse are considered well-established risk factors for oral SCC in older population. Otherwise, in young patients, these classical risk factors cannot be considered as the major ones for oral cancer [10, 17, 32,33], if the period of abuse is not enough to create carcinogenesis [10].

On the other side, some studies report that tobacco use starts during adolescence [10], usually before 16 years old, making probable that before the age of 40 years, patients have an accumulated risk of more than 21 years of consumption, being more susceptible for the oral cancer [34].

Probably, the pathogenesis of oral SCC in young people involves multiple factors, as genetic and others new behavioral factors $[32,33]$. It seems that tobacco and alcohol consumption are not the main etiological factors for oral SCC in young patients.

\subsection{Genetic factors}

Genetic predisposition for cancer development at young age, especially in those patients with no recognized risk factors seems to be preponderant [34]. Chromosome fragility, DNA ploidy abnormalities and increased familial risk of head and neck SCC have already been reported in young patients $[26,34,35]$.

Considering the familial risk, a clear significant relative risk of SCC exists in first-degree family members of those who suffered head and neck cancer [35], especially when there is no recognized risk factor associated. Oral cancer has been associated with higher chromosome fragility and instability in youngsters, compared to elderly [36].

Genetic instability is an important molecular mechanism for head and neck cancers [35]. Gain and loss of specific chromosome regions in DNA are responsible for head and neck cancers, for example the 3p or 9p21 region, which are early events strictly related with head and neck cancer development, but that are not commonly seen in young people [35]. It is supposed that a completely different model of tumorigenesis exists, at a molecular level, in young people.

One essential step for tumorigenesis is deregulation of normal cell cycle regulatory system, especially in genes that control G1 to 2 phase progression in cell cycle [37]. The amplification of the gene CCDN1 was noted to be more expressive in young people [31]. CCDN1 is a protooncogene that encodes cyclin D1, a key regulator of G1 phase in cell cycle. The overexpression of cyclin D1 was found to be more prominent in young people [31], and it was correlated with disease-free survival in younger and elderly patients. Instead of these findings, larger studies are required to confirm the prognostic value of CCDN1 in young patients. 


\subsection{Behavioral and other factors}

\subsubsection{Marijuana consumption}

Several cases reported in the literature [38, 39] suggest an association between marijuana smoking and head and neck cancers and respiratory cancers, but this correlation is not conclusive.

The use of marijuana has been speculated as a risk factor for oral cancer in young people [10]. The main reason is that marijuana smoke contains carcinogens similar to those in tobacco, and marijuana smoking involves greater inhalation and longer retention of marijuana smoke [34]. However, the potential of carcinogenicity of tetrahydrocannabiol (THC), the major psychoactive ingredient in marijuana, is not clear yet [40], but it is evident that cannabinoids have an effect in tumorigenic or antitumorigenic role [41]. The patient with oral SCC illustrated in the Figures 1 and 2 confirmed frequent marijuana use when he was a teenager.

\subsubsection{Immunodeficiencies}

Some chronic immunodeficiency states (Bloom syndrome, Wiskott-Aldrich syndrome), or even immunosuppression regimes following organ transplantation [34] and anemia (Patterson Kelly/ Plummer Vinson syndrome, Fanconi anemia) [35], might play important roles in carcinogenesis in young people. Specifically, Fanconi anemia has an associated higher risk for developing head and neck cancer, estimated to be $40 \%$ by the fourth to sixth decade of life. Mutations in telomerase complex are responsible for Fanconi anemia and regarding its malignant transformation, telomeres are repeatedly shortened precipitating a genetic instability, allowing the progression to a malignant neoplasia [35].

Another distinct group that compound young head and neck cancer patients is those with cancer during childhood. The probability of a second synchronous tumor or metachronous primary tumor is estimated in $3-12 \%$ in 20 years of survival. Also, chemotherapeutic drugs and radiation can induce malignancies as side effects [7, 42].

\subsubsection{Diet}

A well-defined concept is that a diet rich in fruits and vegetables, with antioxidant properties, has a protective role against oral cancer [43]. A significant reduction in the risk of oral SCC was found among females consuming three or more portions of fresh fruits and vegetables daily $[43,44]$. However, this factor is preponderant for the population in general and there are no studies on specific dietary behavior for young people.

\subsubsection{Viral infections}

The human papillomavirus (HPV) comprises a huge group of more than 50 subtypes of viruses able to infect the anogenital region and can be divided into two major subgroups: low-risk and high-risk types for cancer [45]. The low-risk HPVs are usually responsible for genital warts 
that rarely progress into malignancy whereas the high-risk ones have oncogenic capability, leading to the development of cancer. The HPV-16 and HPV-18 are the major high-risk types that are present in anogenital and head and neck cancers [45].

Recent changes in the epidemiological profile of oral carcinoma have encouraged the research for new risk factors related to the development of oral cancer. For example, there has been a decrease in the tobacco-associated oral cancer and an increase of non-smoking white female young patients (18-44 years) who presented with oral SCC [46]. These facts, associated with the established oncogenic power of HPV-16 in cervix carcinoma [47] raised the hypothesis that HPV could be an etiological factor for oral SCC. Moreover, oral mucosa is highly exposed to chemical carcinogens, infections, and trauma, making it more vulnerable to carcinogenesis. Then, it has been postulated that abrasions caused due to this continuous exposure might make this mucosal surface more susceptible to HPV by making it easier for the virus to gain entry into the basal cells of oral mucosa [45].

The mechanism by which the high-risk HPVs promote the carcinogenesis has been already revealed. Once the cell is infected with HPV, the viral oncoproteins E6 and E7 are integrated to the cell genome and their expressions alter the host genome functions [45, 46]. HPV E6 and E7 proteins disrupt p53 and pRb tumor suppressor genes as well as numerous cellular proteins involved in carcinogenesis (BAK, telomerase, INK4A, E2F, cyclins A and E, WAF1, and KIP1) [46]. These accumulated defects in the genomic expression of the infected cells lead to cell immortalization and genomic instability by deactivation of control and regulatory mechanisms of cell apoptosis, cell cycle, and DNA repair $[45,46]$. These mechanisms are essential for the development of cervix carcinoma, once HPV prevalence in this type of cancer is $100 \%$ [48]. The same is true for oropharyngeal SCC, with a HPV prevalence up to $90 \%[49,50]$. In oral SCC, the role of HPV still remains unclear. The anatomical structures of oropharynx, especially the base of the tongue and tonsils, seem to be more susceptible to HPV infection when compared to oral sites [34].

The prevalence of HPV in oral cancer may vary from 0 to 100\% [51] and this may not be only due to ethno-geographical differences but to the sensitivity of the applied diagnostic technique and to the site of the lesion [51]. The first issue to study the HPV prevalence in these lesions is the techniques employed to detect it. The most accurate ones seem to be the polymerase chain reaction for the HPV DNA and in situ hybridization. The immunohistochemistry is also employed but it can lose its accuracy in old specimens [52].

In well-designed studies selected in an elegant review of the literature on the role of HPV in oral SCC, only nine split the groups between young and older people [5, 19, 53-59]. The presence of high-risk HPV had a negative impact for the patient's survival in four studies [5, $19,55,58]$, was neutral in three $[53,54,59]$, and had a positive impact in only one investigation [57]. Putting together all data, there is a clear need of more studies with larger samples and more standardized methodology for the virus detection. Despite of the proved role of HPV in the carcinogenesis of the cervix and oropharynx, it is still difficult to draw any conclusion regarding the role of the high-risk HPV types 16 and 18 in the oral cancer development. 


\section{Treatment}

Most cases of oral SCC in young population occur at the mobile tongue. Treatment of tongue tumors at any age depends on the clinical stage at diagnosis. Surgery and radiotherapy are the standards of care for early-stage and also for locally advanced tumors in the oral cavity. The specific treatment is dictated by the TN stage and, if N0 at diagnosis, by the risk of nodal involvement [60]. For T1N0 tumors, surgical resection is recommended and no adjuvant therapy is necessary. The T2 to T4 N0 tumors require local surgery and supraomohyoid neck dissection. Treatment of the neck is expanded according to the worsening of cervical clinical staging. Postoperative radiotherapy is indicated in the following cases: clinical stage III or IV, presence of compromised or small surgical margins, presence of vascular or perineural infiltration, presence of lymph node involvement or extracapsular spread [61]. At present, there is no recommendation for a different approach on oral tumors in young patients [60].

Kaminagakura et al. [62] described a better overall survival in a group of young patients $(<40-$ year-old) treated after 1991, when compared to similar patients treated earlier. They attributed this finding to the more aggressive and adequate treatment approaches applied and also to an early diagnosis. So, does the treatment of oral SCC of young people need to be more aggressive? This question can be answered only after understanding the evolution and prognosis of this disease affecting young people. There is a suggestion that people under the age of 40 should be treated differently from the older ones. This is based on the finding of high recurrence and low survival rates between the young. [27]. Also, aggressive therapeutic approach for tongue cancer was recommended by Myers et al. [20], with no age distinction. Controversially, Goepfert et al. [6] described that young women ( $<45$ years) with oral SCC had similar prognosis when compared to older men and women with this disease, highlighting the unnecessary adoption of adjuvant therapies in this particular group. Is it time to rethink the aggressive treatments and the use of adjuvant unnecessary therapies [21]?

When over treatment occurs in young people, it may be motivated by emotional aspects involving the diagnosis of a lethal condition in such a young person. Also, a radical option may be influenced by the surgeon's experience rather than by scientific evidence [6]. So, it is of utmost importance to know if these tumors have worse prognosis to justify a more aggressive therapy.

\section{Prognosis}

The outcome for oral SCC occurring in youngsters is a major controversial issue. Various studies have attempted to elucidate the prognostic significance of patient age at diagnosis. Unfortunately, there are no prospective studies comparing elderly and younger patients regarding prognosis. Also, there is no large multicentric research on this topic.

An ordinary question that can greatly affect the results of prognostic studies is the very definition of what would be a young patient with oral SCC. This age limit is empirical and 
most studies use 40-year-old as the cutoff age $[2,4,27,29,30,63,64]$. Some outcome analyses use the age of $30,35,45[3,5-8,15,28,66]$ or even 60 years as the limit to be considered young [67]. Pediatric patients with oral tumors (under 20 years) have also been studied [9]. So, if there is not much consensus on the age of the patients to be considered young, it is quite difficult to achieve consistent results, regarding the prognosis, when comparing these studies.

Some retrospective reports attempted to analyze prognosis for young population with oral SCC, but they did not compare this data to older counterparts [20, 21, 23, 24, 68-76]. Mallet et al. [68] found a high rate of persistent evolution and tumor recurrence within the first year after treatment in a group of patients under 35-year-old, and this affected negatively the overall survival. McGregor et al. [24] reported 80\% cure rate among patients less than 40 years, but similarly to Mallet et al. [68], patients who died from disease usually had a poor response to initial treatment (within the first 2 years). Exceptionally good overall survival for patients $<40$ years had been reported [20,69]. These results suggest a good survival for young patients, albeit with a subgroup of patients developing short term recurrence. The lack of comparison with older counterparts weakened the results, regarding the role of age in prognosis.

The first comparative studies of oral SCC in young and old patients were published in 1998 by Siegelman-Danielli et al. [28] and Friedlander et al. [2]. They found similar outcome between the groups. Subsequently, another 16 reports compared the evolution of young and older patients with oral SCC, only 4 of them reporting worse prognosis. Analyzing these results, it appears that age at diagnosis has no significance in the outcome for oral SCC.

A matched-pair analysis methodology was performed by some of these comparative reports $[2,3,5,6,15,27,62]$. This design aims to match similar patients from 2 different groups (old and young), often by sex and disease stage. So, when matched pairs are analyzed, the matched variables are controlled, highlighting the patient's age as an outcome predictor. Only one matched pair analysis [27] showed worse prognosis for young oral cancer patients. This literature is summarized on Table 1.

Although many authors recognized that early age at diagnosis is not an individual factor that worsened outcome, some important information can be extracted from their results. In general, more young patients have recurred locally and regionally $[2,4,6,22,27,29,30,62-64,65]$. This finding may be explained by two theories: lack of adequate treatment and biologically different behavior. Fang et al. [22] found $60 \%$ of local recurrence in young patients versus $11 \%$ among the older ones, and both groups were treated similarly. Another study observed that most of the recurrent young patients had been initially treated with radiotherapy and that this could be the cause for the high recurrence rate [4]. In fact, the reason for inadequate treatment could be explained by the intention to cause less morbidity because of the lower age. Aggressiveness of the surgical procedure is difficult to compare, mainly because it suffers influence of subjective factors during the surgical act and most of the studies had no information about the margin size and status. However, because of the similar treatment approaches used in young and old patients in most of the reports, it is possible that these tumors have a unique biological behavior that needs to be well understood. Siegelmann-Danieli et al. [28] reported that tumors developed in the absence of tobacco or alcohol occurred more frequently in young patients and that patients at any age who developed disease without these risk factors may have a worse outcome, reinforcing different pathological behavior. 


\begin{tabular}{|c|c|c|c|c|c|c|}
\hline Authors & Year & Country & Cases/controls & Age limit* & Study Design & Outcome \\
\hline Siegelmann-Danieli et al. & 1998 & USA & $30 / 57$ & 45 & Non-matched & Similar \\
\hline Fredlander et al. & 1998 & USA & $36 / 36$ & 40 & $\begin{array}{c}\text { Matched-pair } \\
\text { analysis }\end{array}$ & Similar \\
\hline Pitman et al. & 2000 & USA & $122 / 150$ & 40 & Non-matched & Similar \\
\hline Vargas et al. & 2000 & USA & $17 / 17$ & 40 & Non-matched & $\begin{array}{c}\text { Worse } \\
\text { (women) }\end{array}$ \\
\hline Hyam et al. & 2003 & Australia & $15 / 48 / 60$ & 40 & Non-matched & Similar \\
\hline Veness et al. & 2003 & Australia & $22 / 142$ & 40 & Non-matched & Similar \\
\hline Popovtzer et al. & 2004 & Israel & $16 / 32$ & 45 & $\begin{array}{c}\text { Matched-pair } \\
\text { analysis }\end{array}$ & Similar \\
\hline Liao et al. & 2006 & Taiwan & $76 / 220$ & 40 & Non-matched & Similar \\
\hline Siriwardena et al. & 2007 & Sri Lanka & $56 / 56$ & 40 & Non-matched & $\begin{array}{c}\text { Similar/ } \\
\text { Undefined }\end{array}$ \\
\hline Lee et al. & 2007 & Taiwan & $20 / 20$ & 45 & $\begin{array}{c}\text { Matched-pair } \\
\text { analysis }\end{array}$ & Better \\
\hline Garavelo et al. & 2007 & Italy & $46 / 92$ & 40 & $\begin{array}{c}\text { Matched-pair } \\
\text { analysis }\end{array}$ & Worse \\
\hline Ho et al. & 2008 & Taiwan & $28 / 56$ & 45 & $\begin{array}{c}\text { Matched-pair } \\
\text { analysis }\end{array}$ & Better \\
\hline Morris et al. & 2010 & USA & $10 / 40$ & 20 & Non-matched & Similar \\
\hline Kaminagakura et al. & 2010 & Brazil & $125 / 250$ & 41 & $\begin{array}{c}\text { Matched-pair } \\
\text { analysis }\end{array}$ & Similar \\
\hline Park et al. & 2010 & Korea & $23 / 62$ & 45 & Non-matched & Worse \\
\hline Soudry et al. & 2010 & Israel & $11 / 74$ & 30 & Non-matched & Similar \\
\hline Hilly et al. & 2013 & Israel & $16 / 62$ & 30 & Non-matched & $\begin{array}{c}\text { Worse when } \\
\text { recurrent }\end{array}$ \\
\hline Goepfert et al. & 2014 & USA & $18 / 36$ & 45 & $\begin{array}{c}\text { Matched-pair } \\
\text { analysis }\end{array}$ & Similar \\
\hline Fang et al. & 2014 & China & $15 / 161$ & 40 & Non-matched & Similar \\
\hline
\end{tabular}

*age limit for the young patient's group.

Table 1. Literature review of comparative studies evaluating younger age as a predictor of outcome in oral SCC.

Another interesting fact is that young patients recurred earlier [3,64] and a high percentage of these recurrent young patients died of their disease [2, 3, 8, 22, 27]. A high index of recurrent disease associated with fatality was observed in the reports of Friedlander et al. [2] and Hilly et al. [8] ( $90 \%$ and 100\%, respectively) and early fatality in $40 \%$ was reported by Popovtzer et al. [3] (within the two first years). 
Moreover, there is some evidence that young patients developed more distant metastasis than the older counterparts $[7,66]$. No strong known predicting factors for distant metastasis was found [65] and the observation of $100 \%$ incidence of death in distant failure patients indicated that young patients more often present with more advanced disease and may have a distinct pattern of recurrence [7]. Controversially, Fang et al. [22] observed 66\% of locoregional recurrence without a single distant metastasis in a group of young patients $(n=15)$.

Some recognized microscopic adverse risk features for oral SCC are the extracapsular nodal spread, positive margins, perineural invasion, and vascular embolism [60]. Unfortunately, there is lack of information on microscopic status of the tumors in many reports $[3,5,9,63,64,66]$. Perineural invasion was found to be similar between groups of young and old patients $[7,8]$. Siegelmann-Danieli et al.[28] found similar extracapsular involvement in both groups, while Hilly et al. [8] and Soudry et al. [7] found higher, but not significant, index of extracapsular spread in young patients with nodal disease. There is evidence that cellular differentiation, depth of tumor, nerve invasion and extracapsular spread of the involved lymph node were risk factors for distant metastasis in young population with oral cancer. However, these characteristics were not exclusive for young patients [65]. Studies failed to correlate extracapsular involvement, differentiation and perineural invasion to worse outcome in the young $[7,8]$.

The correlation between the expression of Ki-67, cyclin D1, p16, PCNA, EGFR and angiogenesis with outcome was investigated in young oral cancer population [31, 58, 69, 77, 78]. Overexpression of Ki-67, a cell proliferation marker, was similar in both young and old patients. Angiogenesis also had a similar rate [77]. Moreover, the high expression of cyclin D1 was an indicator of worsened prognosis in both young and old groups [31]. P16 was a marker of favorable prognosis among young population, although not a reliable predictor of HPV presence [58]. A significantly increased number of mitosis, accompanied by strong PCNA expression and higher number of metastasis in the older group were found by Siriwardena $e t$ al. [78]. The authors believe that oral SCC in the older group is more proliferative, compared with younger patients. Low levels of EGFR expression were associated with lower recurrence rate in young patients, and those with high levels of expression had adverse prognosis [69]. Although there are microscopic factors recognizably influencing prognosis, the available studies failed to demonstrate them in oral cancer affecting young population. These results may be partially explained by the small groups analyzed. The immunoprofile of these tumors are yet to be elucidated, and it appears to be a promising area of research.

A common limitation to all the comparative studies of oral cancer in young people is the small population analyzed, since SCC of the oral cavity is a rare tumor. The largest group of young patients in a single hospital was 125 people at Brazil, but unfortunately the high rates of T3 and T4 disease made this group quite different from the other ones [62]. Pitmann et al. [63] studied 122 cases, but their population was not uniform, since 94 of these patients were extracted from previous literature reports. The lower the cutoff age, the lower the sample size. Morris et al. [9] and Soudry et al. [7] studied only 10 patients ( $<20$ years $)$ and 11 patients $(<20$ years), respectively. 


\section{Conclusions}

Oral SCC in young people accounts for about $0.4-2.6 \%$ of the total incidence and has a slight predominance in men. The most common location for this tumor is the tongue and occurrence of symptoms is rare unless the lesion reaches a wide size. The delay before diagnosis varies from few weeks to approximately 10 months.

Concerning the etiological factors for oral SCC in young adults who do not smoke and drink alcohol frequently, genetic abnormalities seem to have a preponderant role in development of the tumor. Additionally, human papilloma virus infection, specifically by HPV-16 and HPV-18, are more frequently detected in this group, but more studies are needed to confirm its influence in prognosis and clinical outcome of oral SCC in the younger.

In the light of current knowledge, it is possible to affirm that age is not an independent outcome predictor for oral SCC. However, a group of young patients that develops a more aggressive disease with a recurrent pattern seems to exist. In this group, early death is common. It is not possible yet to point out the causes for this aggressive behavior. Supported by published studies, treatment should be aggressive for both younger and older patients, and there is no rationale for different approach in young population with oral SCC. Also, further multicentric studies with standardized treatment protocols are necessary in order to elucidate the controversies of this fatal and increasing disease.

\section{Author details}

Ligia Buloto Schmitd $^{1,2}$, Kellen Cristine Tjioe ${ }^{1}$, Agnes Assao ${ }^{1}$ and Denise Tostes Oliveira ${ }^{1 *}$

*Address all correspondence to: d.tostes@fob.usp.br

1 Department of Stomatology, Pathology Division, Bauru School of Dentistry, University of São Paulo, Bauru, SP, Brazil

2 Department of Stomatology, FAESA Dental School, Vitória, ES, Brazil

\section{References}

[1] Patel SC, Carpenter WR, Tyree S, Couch ME, Weissler M, Hackman T, Hayes DN, Shores C, Chera BS. Increasing Incidence of Oral Tongue Squamous Cell Carcinoma in Young White Women, Age 18 to 44 Years. Journal of Clinical Oncology 2011; 29(11) 1488-1494. 
[2] Friedlander PL, Schantz SP, Shaha AR, Yu G, Shah JP. Squamous Cell Carcinoma of the Tongue in Young Patients: a Matched-Pair Analysis. Head \& Neck 1998; 20(5) 363-368.

[3] Popovtzer A, Shpitzer T, Bahar G, Marshak G, Ulanovski D, Feinmesser R. Squamous Cell Carcinoma of the Oral Tongue in Young Patients. Laryngoscope 2004; 114(5) 915-917.

[4] Siriwardena BS, Tilakaratne A, Amaratunga EA, Tilakaratne WM. Demographic, Aetiological and Survival Differences of Oral Squamous Cell Carcinoma in the Young and the Old in Sri Lanka. Oral Oncology 2006; 42(8) 831-836.

[5] Lee LA, Huang CG, Liao CT, Lee LY, Hsueh C, Chen TC, Lin CY, Fan KH, Wang HM, Huang SF, Chen IH, Kang CJ, Ng SH, Yang SL, Tsao KC, Chang YL, Yen TC. Human Papillomavirus-16 Infection in Advanced Oral Cavity Cancer Patients Is Related to an Increased Risk of Distant Metastases and Poor Survival. PloS One 2012; 7(7) e40767.

[6] Goepfert RP, Kezirian EJ, Wang SJ. Oral Tongue Squamous Cell Carcinoma in Young Women: a Matched Comparison - Do Outcomes Justify Treatment Intensity? ISRN Otolaryngology 2014; 10 ID529395.

[7] Soudry E, Preis M, Hod R, Hamzany Y, Hadar T, Bahar G, Strenov Y, Shpitzer T. Squamous Cell Carcinoma of the Oral Tongue in Patients Younger Than 30 Years: Clinicopathologic Features and Outcome. Clinical Otolaryngology 2010; 35(4) 307-312.

[8] Hilly O, Shkedy Y, Hod R, Soudry E, Mizrachi A, Hamzany Y, Bachar G, Shpitzer T. Carcinoma of the Oral Tongue in Patients Younger Than 30 Years: Comparison with Patients Older Than 60 Years. Oral Oncology 2013; 49(10) 987-990.

[9] Morris LG, Ganly I. Outcomes of Oral Cavity Squamous Cell Carcinoma in Pediatric Patients. Oral Oncology 2010; 46(4) 292-296.

[10] Llewellyn CD, Johnson NW, Warnakulasuriya KA. Risk Factors for Squamous Cell Carcinoma of the Oral Cavity in Young People - a Comprehensive Literature Review. Oral Oncology 2001; 37(5) 401-418.

[11] Halboub E, Al-Mohaya M, Abdulhuq M, Al-Mandili A, Al-Anazi Y. Oral Squamous Cell Carcinoma Among Yemenis: Onset in Young Age and Presentation at Advanced Stage. Journal of Clinical and Experimental Dentistry 2012; 4(4) e221-e225.

[12] Ribeiro AC, Silva AR, Simonato LE, Salzedas LM, Sundefeld ML, Soubhia AM. Clinical and Histopathological Analysis of Oral Squamous Cell Carcinoma in Young People: a Descriptive Study in Brazilians. The British Journal of Oral \& Maxillofacial Surgery 2009; 47(2) 95-98. 
[13] O'Regan EM, Timon C, Sheils O, Codd M, O'Leary JJ, Toner M. Squamous Cell Carcinoma of the Head and Neck in Young Irish Adults. The British Journal of Oral \& Maxillofacial Surgery 2006; 44(3) 203-206.

[14] Shiboski CH, Schmidt BL, Jordan RC. Tongue and Tonsil Carcinoma: Increasing Trends in the U.S. Population Ages 20-44 Years. Cancer 2005; 103(9) 1843-1849.

[15] Ho HC, Lee MS, Hsiao SH, Hwang JH, Hung SK, Chou P, Lee CC. Squamous Cell Carcinoma of the Oral Cavity in Young Patients: a Matched-Pair Analysis. European Archives of Oto-Rhino-Laryngology 2008; 265(1 Suppl) S57-S61.

[16] Udeabor SE, Rana M, Wegener G, Gellrich NC, Eckardt AM. Squamous Cell Carcinoma of the Oral Cavity and the Oropharynx in Patients Less Than 40 Years of Age: a 20-Year Analysis. Head \& Neck Oncology 2012; 428.

[17] Kuriakose M, Sankaranarayanan M, Nair MK, Cherian T, Sugar AW, Scully C, Prime SS. Comparison of Oral Squamous Cell Carcinoma in Younger and Older Patients in India. European Journal of Cancer, Part B. Oral Oncology 1992; 28B(2) 113-120.

[18] Falaki F, Dalirsani Z, Pakfetrat A, Falaki A, Saghravanian N, Nosratzehi T, Pazouki M. Clinical and Histopathological Analysis of Oral Squamous Cell Carcinoma of Young Patients in Mashhad, Iran: a Retrospective Study and Review of Literature. Medicina Oral, Patologia Oral y Cirugia Bucal 2011; 16(4) e473-e477.

[19] Sharma A, Mendez E, Yueh B, Lohavanichbutr P, Houck J, Doody DR, Futran ND, Upton MP, Schwartz SM, Chen C. Human Papillomavirus-Positive Oral Cavity and Oropharyngeal Cancer Patients Do Not Have Better Quality-of-Life Trajectories. Otolaryngology - Head and Neck Surgery 2012; 146(5) 739-745.

[20] Myers JN, Elkins T, Roberts D, Byers RM. Squamous Cell Carcinoma of the Tongue in Young Adults: Increasing Incidence and Factors that Predict Treatment Outcomes. Otolaryngology - Head and Neck Surgery 2000; 122(1) 44-51.

[21] Manuel S, Raghavan SK, Pandey M, Sebastian P. Survival in Patients Under 45 Years with Squamous Cell Carcinoma of the Oral Tongue. International Journal of Oral and Maxillofacial Surgery 2003; 32(2) 167-173.

[22] Fang QG, Shi S, Liu FY, Sun CF. Tongue Squamous Cell Carcinoma as a Possible Distinct Entity in Patients Under 40 Years Old. Oncology Letters 2014; 7(6) 2099-2102.

[23] Venables CW, Craft IL. Carcinoma of the Tongue in Early Adult Life. British Journal of Cancer 1967; 21(4) 645-650.

[24] McGregor GI, Davis N, Robins RE. Squamous Cell Carcinoma of the Tongue and Lower Oral Cavity in Patients Under 40 Years of Age. American Journal of Surgery 1983; 146(1) 88-92. 
[25] Barnes L, Everson JW, Reichart P, Sidransky D. World Health Organization Classification of Tumors. Pathology and Genetics of Head and Neck Tumors. IARC Press: Lyon 2005.

[26] Santos-Silva AR, Ribeiro AC, Soubhia AM, Miyahara GI, Carlos R, Speight PM, Hunter KD, Torres-Rendon A, Vargas PA, Lopes MA. High Incidences of DNA Ploidy Abnormalities in Tongue Squamous Cell Carcinoma of Young Patients: an International Collaborative Study. Histopathology 2011; 58(7) 1127-1135.

[27] Garavello W, Spreafico R, Gaini RM. Oral Tongue Cancer in Young Patients: a Matched Analysis. Oral Oncology 2007; 43(9) 894-897.

[28] Siegelmann-Danieli N, Hanlon A, Ridge JA, Padmore R, Fein DA, Langer CJ. Oral Tongue Cancer in Patients Less Than 45 Years Old: Institutional Experience and Comparison with Older Patients. Journal of Clinical Oncology 1998; 16(2) 745-753.

[29] Veness MJ, Morgan GJ, Sathiyaseelan Y, Gebski V. Anterior Tongue Cancer: Age Is Not a Predictor of Outcome and Should Not Alter Treatment. ANZ Journal of Surgery 2003; 73(11) 899-904.

[30] Hyam DM, Conway RC, Sathiyaseelan Y, Gebski V, Morgan GJ, Walker DM, Veness MJ. Tongue Cancer: do Patients Younger Than 40 Do Worse? Australian Dental Journal 2003; 48(1) 50-54.

[31] Kaminagakura E, Werneck da Cunha I, Soares FA, Nishimoto IN, Kowalski LP. CCND1 Amplification and Protein Overexpression in Oral Squamous Cell Carcinoma of Young Patients. Head \& Neck 2011; 33(10) 1413-1419.

[32] Bodner E, Palgi Y, Kaveh D. Does the Relationship Between Affect Complexity and Self-esteem Differ in Young-Old and Old-Old Participants? The Journals of Gerontology. Series B, Psychological Sciences and Social Sciences 2013; 68(5) 665-673.

[33] Turi K, Barabas P, Csurgay K, Lehner GY, Lorincz A, Nemeth ZS. An Analysis of the Epidemiological and Etiological Factors of Oral Tumors of Young Adults in a Central-Eastern European Population. Pathology \& Oncology Research 2013; 19(3) 353-363.

[34] Majchrzak E, Szybiak B, Wegner A, Pienkowski P, Pazdrowski J, Luczewski L, Sowka M, Golusinski P, Malicki J, Golusinski W. Oral Cavity and Oropharyngeal Squamous Cell Carcinoma in Young Adults: a Review of the Literature. Radiology and Oncology 2014; 48(1) 1-10.

[35] Toner M, O'Regan EM. Head and Neck Squamous Cell Carcinoma in the Young: a Spectrum or a Distinct Group? Part 1. Head and Neck Pathology 2009; 3(3) 246-248.

[36] Kostrzewska-Poczekaj M, Gawecki W, Illmer J, Rydzanicz M, Gajecka M, Szyfter W, Szyfter K. Polymorphisms of DNA Repair Genes and Risk of Squamous Cell Carcinoma of the Head and Neck in Young Adults. European Archives of Oto-Rhino-Laryngology 2013; 270(1) 271-276. 
[37] Scully C, Field JK, Tanzawa H. Genetic Aberrations in Oral or Head and Neck Squamous Cell Carcinoma (SCCHN): 1. Carcinogen Metabolism, DNA Repair and Cell Cycle Control. Oral Oncology 2000; 36(3) 256-263.

[38] Zhang ZF, Morgenstern H, Spitz MR, Tashkin DP, Yu GP, Marshall JR, Hsu TC, Schantz SP. Marijuana Use and Increased Risk of Squamous Cell Carcinoma of the Head and Neck. Cancer Epidemiology, Biomarkers \& Prevention 1999; 8(12) 1071-1078.

[39] Hashibe M, Ford DE, Zhang ZF. Marijuana Smoking and Head and Neck Cancer. Journal of Clinical Pharmacology 2002; 42(11 Suppl) 103S-107S.

[40] Guzman M. Cannabinoids: Potential Anticancer Agents. Nature Reviews. Cancer $2003 ; 3(11)$ 745-755.

[41] Liang C, McClean MD, Marsit C, Christensen B, Peters E, Nelson HH, Kelsey KT. A Population-Based Case-Control Study of Marijuana Use and Head and Neck Squamous Cell Carcinoma. Cancer Prevention Research 2009; 2(8) 759-768.

[42] Curado MP, Hashibe M. Recent Changes in the Epidemiology of Head and Neck Cancer. Current Opinion in Oncology 2009; 21(3) 194-200.

[43] Llewellyn CD, Linklater K, Bell J, Johnson NW, Warnakulasuriya S. An Analysis of Risk Factors for Oral Cancer in Young People: a Case-Control Study. Oral Oncology 2004 Mar; 40(3) 304-313.

[44] Rodriguez T, Altieri A, Chatenoud L, Gallus S, Bosetti C, Negri E, Franceschi S, Levi F, Talamini R, La Vecchia C. Risk Factors for Oral and Pharyngeal Cancer in Young Adults. Oral Oncology 2004; 40(2) 207-213.

[45] Chocolatewala NM, Chaturvedi P. Role of Human Papilloma Virus in the Oral Carcinogenesis: an Indian Perspective. Journal of Cancer Research and Therapeutics 2009; 5(2) 71-77.

[46] Kansy K, Thiele O, Freier K. The Role of Human Papillomavirus in Oral Squamous Cell Carcinoma: Myth and Reality. Oral and Maxillofacial Surgery 2014; 18(2) 165-172.

[47] Durst M, Gissmann L, Ikenberg H, zur Hausen H. A Papillomavirus DNA from a Cervical Carcinoma and Its Prevalence in Cancer Biopsy Samples from Different Geographic Regions. Proceedings of the National Academy of Sciences of the United States of America 1983; 80(12) 3812-3815.

[48] Stanley M. Pathology and Epidemiology of HPV Infection in Females. Gynecologic Oncology 2010; 117(2 Suppl) S5-S10.

[49] Gillison ML, Koch WM, Capone RB, Spafford M, Westra WH, Wu L, Zahurak ML, Daniel RW, Viglione M, Symer DE, Shah KV, Sidransky D. Evidence for a Causal As- 
sociation Between Human Papillomavirus and a Subset of Head and Neck Cancers. Journal of the National Cancer Institute 2000; 92(9) 709-720.

[50] Marur S, D'Souza G, Westra WH, Forastiere AA. HPV-Associated Head and Neck Cancer: a Virus-Related Cancer Epidemic. The Lancet Oncology 2010; 11(8) 781-789.

[51] Termine N, Panzarella V, Falaschini S, Russo A, Matranga D, Lo Muzio L, Campisi G. HPV in Oral Squamous Cell Carcinoma vs Head and Neck Squamous Cell Carcinoma Biopsies: a Meta-Analysis (1988-2007). Annals of Oncology 2008; 19(10) 1681-1690.

[52] Kaminagakura E, Villa LL, Andreoli MA, Sobrinho JS, Vartanian JG, Soares FA, Nishimoto IN, Rocha R, Kowalski LP. High-Risk Human Papillomavirus in Oral Squamous Cell Carcinoma of Young Patients. International Journal of Cancer 2012; 130(8) 1726-1732.

[53] Campisi G, Giovannelli L, Calvino F, Matranga D, Colella G, Di Liberto C, Capra G, Leao JC, Lo Muzio L, Capogreco M, D'Angelo M. HPV Infection in Relation to OSCC Histological Grading and TNM Stage. Evaluation by Traditional Statistics and Fuzzy Logic Model. Oral Oncology 2006; 42(6) 638-645.

[54] D'Souza G, Zhang HH, D'Souza WD, Meyer RR, Gillison ML. Moderate Predictive Value of Demographic and Behavioral Characteristics for a Diagnosis of HPV16-Positive and HPV16-Negative Head and Neck Cancer. Oral Oncology 2010; 46(2) 100-104.

[55] Duray A, Descamps G, Decaestecker C, Remmelink M, Sirtaine N, Lechien J, ErnouxNeufcoeur P, Bletard N, Somja J, Depuydt CE, Delvenne P, Saussez S. Human Papillomavirus DNA Strongly Correlates with a Poorer Prognosis in Oral Cavity Carcinoma. The Laryngoscope 2012; 122(7) 1558-1565.

[56] El-Mofty SK, Lu DW. Prevalence of Human Papillomavirus Type 16 DNA in Squamous Cell Carcinoma of the Palatine Tonsil, and Not the Oral Cavity, in Young Patients: a Distinct Clinicopathologic and Molecular Disease Entity. The American Journal of Surgical Pathology 2003; 27(11) 1463-1470.

[57] Gillison ML, D'Souza G, Westra W, Sugar E, Xiao W, Begum S, Viscidi R. Distinct Risk Factor Profiles for Human Papillomavirus Type 16-Positive and Human Papillomavirus Type 16-Negative Head and Neck Cancers. Journal of the National Cancer Institute 2008; 100(6) 407-420.

[58] Harris SL, Thorne LB, Seaman WT, Hayes DN, Couch ME, Kimple RJ. Association of p16(INK4a) Overexpression with Improved Outcomes in Young Patients with Squamous Cell Cancers of the Oral Tongue. Head \& Neck 2011; 33(11) 1622-1627.

[59] Marques-Silva L, Farias LC, Fraga CA, de Oliveira MV, Cardos CM, Fonseca-Silva T, Gomes CC, De-Paula AM, Gomez RS, Guimaraes AL. HPV-16/18 Detection Does Not Affect the Prognosis of Head and Neck Squamous Cell Carcinoma in Younger and Older Patients. Oncology Letters 2012; 3(4) 945-949. 
[60] NCCN Clinical Practice Guidelines in Oncology. Head and Neck Cancers Version 2.2014. http://www.nccn.org/professionals/physician_gls/pdf/head-and-neck.pdf

[61] Kowalsky LP, Carvalho AL, Pellizon ACA. Carcinoma de Boca. In: Kowalsky LP et al. (Eds.) Manual de Condutas Diagnósticas e Terapêuticas em Oncologia. Ambito Editores: São Paulo 2002. pp. 411-416.

[62] Kaminagakura E, Vartanian JG, Silva SD, Santos CR, Kowalski LP. Case Control Study on Prognostic Factors in Oral Squamous Cell Carcinoma in Young Patients. Head \& Neck 2010; 32(11) 1460-1466.

[63] Pitman KT, Johnson JT, Wagner RL, Myers EN. Cancer of the Tongue in Patients Less Than Forty. Head \& Neck 2000; 22(3) 297-302.

[64] Vargas H, Pitman KT, Johnson JT, Galati LT. More Aggressive Behavior of Squamous Cell Carcinoma of the Anterior Tongue in Young Women. Laryngoscope 2000; 110(10 Pt 1) 1623-1626.

[65] Park JO, Sun DI, Cho KJ, Joo YH, Yoo HJ, Kim MS. Clinical Outcome of Squamous Cell Carcinoma of the Tongue in Young Patients: a Stage-Matched Comparative Analysis. Clinical and Experimental Otorhinolaryngology 2010; 3(3) c161-c165.

[66] Liao CT, Wang HM, Hsieh LL, Chang JT, Ng SH, Hsueh C, Lee LY, Lin CH, Chen IH, Kang CJ, Huang SF, Yen TC. Higher Distant Failure in Young Age Tongue Cancer Patients. Oral Oncology 2006; 42(7) 718-725.

[67] Vered M, Dayan D, Dobriyan A, Yahalom R, Shalmon B, Barshack I, Bedrin L, Talmi YP, Taicher S. Oral Tongue Squamous Cell Carcinoma: Recurrent Disease Is Associated with Histopathologic Risk Score and Young Age. Journal of Cancer Research and Clinical Oncology 2010; 136(7) 1039-1048.

[68] Mallet Y, Avalos N, Le Ridant AM, Gangloff P, Moriniere S, Rame JP, Poissonnet G, Makeieff M, Cosmidis A, Babin E, Barry B, Fournier C. Head and Neck Cancer in Young People: a Series of 52 SCCs of the Oral Tongue in Patients Aged 35 Years or Less. Acta Oto-Laryngologica 2009; 129(12) 1503-1508.

[69] Thomas L, Moore EJ, McGree ME, Olsen KD, Kasperbauer JL, Erickson LA, Schembri-Wismayer DJ. Prognostic Features, Human Papillomavirus Status, and Epidermal Growth Factor Receptor Expression in Oral Squamous Cell Carcinoma in Young Adults. American Journal of Otolaryngology 2012; 33(6) 650-656.

[70] Sarkaria JN, Harari PM. Oral Tongue Cancer in Young Adults Less Than 40 Years of Age: Rationale for Aggressive Therapy. Head \& Neck 1994; 16(2) 107-111.

[71] Brägelmann J, Dagogo-Jack I, El Dinali M, Stricker T, Brown CD, Zuo Z, Khattri A, Keck M, McNerney ME, Longnecker R, Bieging K, Kocherginsky M, Alexander K, Salgia R, Lingen MW, Vokes EE, White KP, Cohen EE, Seiwert TY. Oral Cavity Tumors in Younger Patients Show a Poor Prognosis and Do Not Contain Viral RNA. Oral Oncology 2013; 49(6) 525-533. 
[72] Newman AN, Rice DH, Ossoff RH, Sisson GA. Carcinoma of the Tongue in Persons Younger Than 30 Years of Age. Archives of Otolaryngology 1983; 109(5) 302-304.

[73] Amsterdam JT, Strawitz JG. Squamous Cell Carcinoma of the Oral Cavity in Young Adults. Journal of Surgical Oncology 1982; 19(2) 65-68.

[74] Iype EM, Pandey M, Mathew A, Thomas G, Nair MK. Squamous Cell Cancer of the Buccal Mucosa in Young Adults. The British Journal of Oral and Maxillofacial Surgery $2004 ; 42(3)$ 185-189.

[75] Byers RM. Squamous Cell Carcinoma of the Oral Tongue in Patients Less Than Thirty Years of Age. The American Journal of Surgery 1975; 130(4) 475-478.

[76] Davidson BJ, Root WA, Trock BJ. Age and Survival from Squamous Cell Carcinoma of the Oral Tongue. Head \& Neck 2001; 23(4) 273-279.

[77] Benevenuto TG, Nonaka CF, Pinto LP, de Souza LB. Immunohistochemical Comparative Analysis of Cell Proliferation and Angiogenic Index in Squamous Cell Carcinomas of the Tongue Between Young and Older Patients. Applied Immunohistochemistry \& Molecular Morphology 2012; 20(3) 291-297.

[78] Siriwardena BS, Tilakaratne A, Amaratunga EA, Udagama MN, Ogawa I, Kudo Y, Takata T, Tilakaratne WM. Analysis of Histopathological and Immunohistochemical Differences of Oral Squamous Cell Carcinoma in Young and Old Patients in Sri Lanka. Journal of Oral Pathology \& Medicine 2007; 36(6) 357-362. 
